\title{
PREDICTION OF TOOL WEAR DURING TURNING OF EN9 WORK MATERIAL AGAINST COATED CARBIDE INSERT USING VIBRATION SIGNAL PROCESSING
}

\author{
Mohamed Khaisar ${ }^{1}$, Godfrey Devaputra ${ }^{2}$ \\ ${ }^{I}$ Professor, Department of Mechanical Engineering, Maharaja Institute of Technology, Mysore, Karnataka, India \\ ${ }^{2}$ Professor, Department of Mechanical Engineering, Maharaja Institute of Technology, Mysore, Karnataka, India
}

\begin{abstract}
In this era of high technology maintenance management systems, condition based maintenance (CBM) is extensively acknowledged. It seeks optimum utilization of the system without altering the quality. The state of a single point cutting tool, w.r.t wear if unobserved while functioning, may affect quality adversely. Condition monitoring helps to establish trend. It can be used to define the tool life in terms of the measured parameter like force, pressure, voltage, vibration etc. Condition monitoring plays a vital role in monitoring the condition of critical parts. In this research work, turning operation is selected with the various work material and tool combination while machining En-9 steels with coated carbide insert as the cutting tool. More precisely, it is the flank wear in the cutting tool, which is concentrated upon in this research work as it is one of the most significant parameter in analyzing the effects of condition monitoring. The research work exhibits important information such as the relationship between tool wear and tool vibration acceleration, time and tool wear and number of cuts and tool wear. The outcome of the research work also delivers with the trend generation that helps monitoring the condition of the cutting tool and also in the prediction of the tool life.
\end{abstract}

Keywords: Turning, Tool Wear, Vibration, Flank Wear, En-9 Steel, Coated Carbide Inserts $* * *$

\section{INTRODUCTION}

Man has always dreamt of an unmanned factory that calls for automation of all the facilities. In the process of automation, the up-keeping of all the facilities to a good working condition is a major challenge [3]. Moreover, the unscheduled breakdowns also become a major issue. The most acceptable solution to these problems of automation and unscheduled breakdowns is condition monitoring technique of maintaining the facilities. The intensity in applicability of condition monitoring ranges from a small component to the entire plant. Condition monitoring is also an important technique in the production centers not only to monitor the machine set ups but also to monitor the cutting tool conditions [4].This is because of the fact that, if tool continued to be used without knowing their condition, then we are risking on the quality of the product being produced. Among all the parameters, the tool wear is the most important parameter leading to the tool failure [1] [2]. The tool wears out in several ways such as flank wear, crater wear, and nose wear etc. Flank wear is the more significant type of tool wear because of its impact and influence of tool life as well the ease of measurement. The width of the flank wear land is a suitable tool wear measure and a predetermined value of flank wear is regarded as a good tool-life criterion. In this research work, turning operation is selected with the various work material and tool combination while machining En-9 steels with uncoated carbide insert as the cutting tool [9]. During the turning operation the flank wear, tool vibration acceleration, time and number of cuts is measured. The correlation between flank wear and vibration acceleration, flank wear and time is established.

\section{OBJECTIVE}

The main objective of the study is to develop a trend plot of tool wear v/s tool vibration amplitude. A correlation is intended to be established with the vibration signals [6] generated during the turning process, also to assess the tool in terms of tool life in min. The study is to be conducted until a max flank wear of $0.6 \mathrm{~mm}$ is reached. Tool wear is to be monitored using frequency analysis of the output signals for assessing the on-line monitoring of tool wear [5]. It is intended to develop a methodology to monitor tool wear in-turn tool life without disturbing the working of the cutting tool during turning. Different types of wear of cutting tool are shown in fig $1[8]$. 


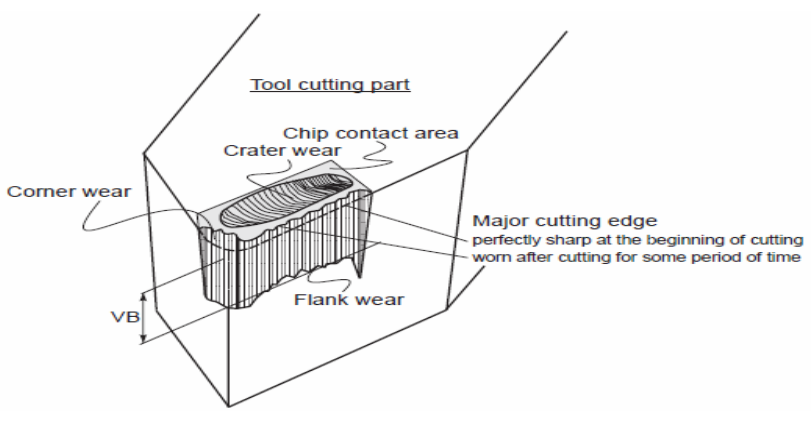

Fig 1: Different types of wear of cutting tool [8]

\section{METHODOLOGY}

\subsection{Work Material}

EN-9 is cut to the sizes of $30 \mathrm{~mm}$ diameter and $300 \mathrm{~mm}$ length with reference to the turning operation without built-up edge formation on the tool tip to the cutting speeds selected. The combinations for the various process parameters to conduct experimentation are as shown in fig-2. The description of each of the process parameters are explained in Section 5

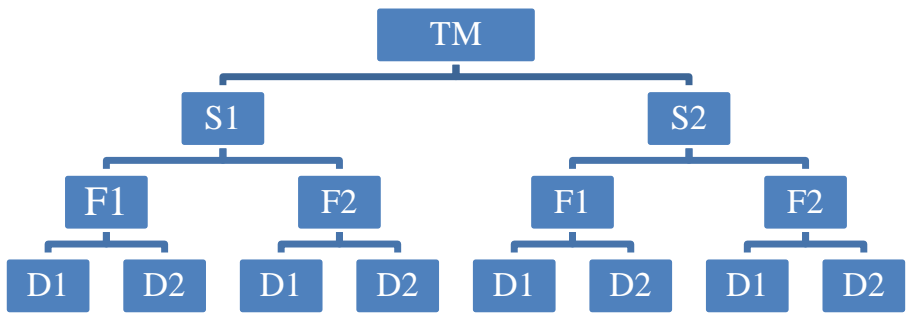

Fig 2: Process parameter combination Tree

\subsection{Cutting Tool}

Coated carbide inserts are used for machining purposes to obtain good surface finish.

\subsection{Operating Conditions}

It is planned to carry out the turning operation of the above work material against the cutting tool as mentioned above. The operating conditions that are

- Two speeds $630 \mathrm{rpm}(59.37 \mathrm{~m} / \mathrm{min})$ and $800 \mathrm{rpm}$ $(75.398 \mathrm{~m} / \mathrm{min})$

- Two feeds $0.07 \mathrm{~mm} / \mathrm{rev}$ and $1.0 \mathrm{~mm} / \mathrm{rev}$

The above mentioned parameters are combined in various combinations and turning was carried out.

\subsection{Data Collection}

In each trial, the following data is collected

- Cutting time in minutes

- Number of cuts
- Vibration acceleration in g's from the vibration signatures obtained from the IRD Model 880 Vibration analyzer at the operating frequency of the tool which has been found before the commencement of the experimentation. The Vibration acceleration is picked up by the accelerometer IRD 970 whose probe is held very closely to the tool tip while turning [12].

- Progressive flank wear is measured at the end of each cut using tool maker's microscope

- With the references of ISO 3685-1993, the above process is to be carried out until the tool has reached the width of flank wear of $06 \mathrm{~mm}$ [7].

- The number of trials and various combinations are planned under different operating conditions using Taguchi's L8 orthogonal array.

\section{EXPERIMENTAL SET UP}

An 18 Speed Automatic Kirloskar lathe was used for conducting the experimentation of turning operation. The cutting tool used was coated cemented carbide inserts against the work material $0.5 \%$ carbon tool steel En9. (12) The operating conditions were set at 2 speeds and 2 depths of cut. The vibration analyzer IRD model 880 with provision to obtain vibration signature in the form of print out was used. To sense the pick up and vibration an IRD model 970 accelerometer was used. A tool maker's microscope was used to measure the flank wear after each trial. The experimental set up is shown in fig 3.

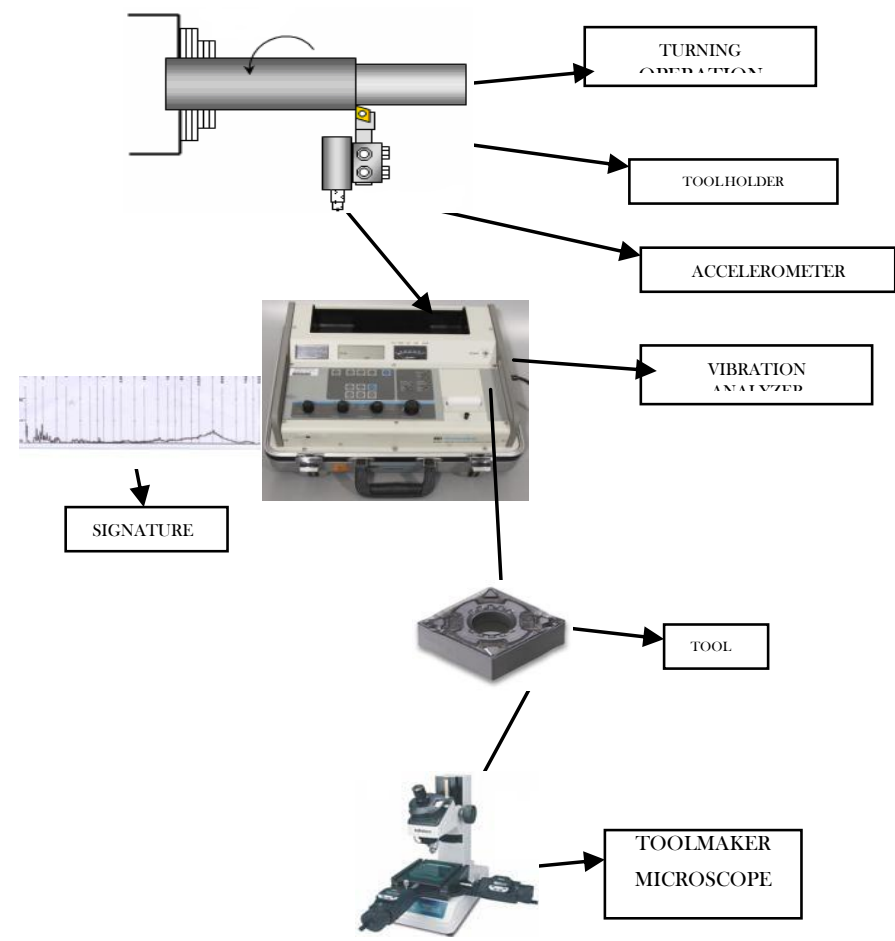

Fig 3: Experimental Set Up. 


\section{PROCESS PARAMETERS}

The process parameters set are,

\begin{tabular}{|l|l|}
\hline $\begin{array}{l}\text { Tool - Coated carbide insert ISO code: } \\
\text { CNMG 12 04 08 TTS }\end{array}$ & $\mathrm{T}$ \\
\hline Tool Holder & PCLNR 1616 \\
\hline Work material- Tool Steel En9 $(0.5 \% \mathrm{C})$ & $\mathrm{M}$ \\
\hline Speed 1: $630 \mathrm{rpm}$ & $\mathrm{S} 1$ \\
\hline Speed 2: $800 \mathrm{rpm}$ & $\mathrm{S} 2$ \\
\hline Feed 1: $0.07 \mathrm{~mm} / \mathrm{rev}$ & $\mathrm{F} 1$ \\
\hline Feed 2: $0.1 \mathrm{~mm} / \mathrm{rev}$ & $\mathrm{F} 2$ \\
\hline Depth of cut $1: 04 \mathrm{~mm}$ & $\mathrm{D} 1$ \\
\hline Depth of cut 2: $08 \mathrm{~mm}$ & $\mathrm{D} 2$ \\
\hline Tool Overhang & $40 \mathrm{~mm}$ \\
\hline Cutting Environment & Dry Cutting \\
\hline
\end{tabular}

\section{EXPERIMENTATION TRIALS}

Using Taguchi's L8 orthogonal array, It was possible to optimize the combinations of too, material, speed, feed and depth of cut and number of trials to 8. (10) They are as follows.

S1F1D1

S1F2D1

S2F1D1

S2F2D1

S1F1D2

S1F2D2

S2F1D2

$\mathrm{S} 2 \mathrm{~F} 2 \mathrm{D} 2$

\section{FREQUENCY ANALYSIS}

First, the natural frequency of the tool holder was determined by the impulse response testing method and it was found that the natural frequency of vibration was $44.5 \mathrm{kHz}$ for tool holder with overhanging length of $0.06 \mathrm{~mm}$. the conformity was obtained experimentally during idle running it was found to be $50 \mathrm{kHz}$.

During machining after several repetitions, the vibration acceleration due to tool was found in the frequencies at about $200 \mathrm{kHz}$ as shown in the figure 4. A prominent in the vibration signatures was found in all the repetitive trials. This can be attributed to the tool vibrations since the accelerometer was attached at the closest distance to the tool tip by strong magnetized stud.

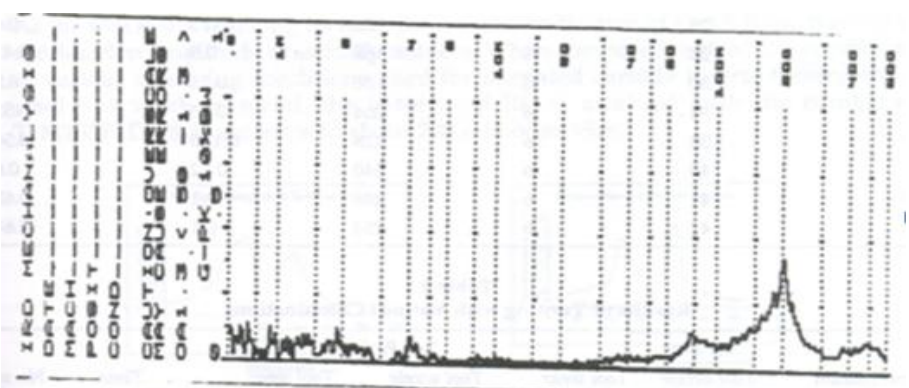

Fig 4: Tool Signature during Machining

\section{EXPERIMENTATION AND RESULTS}

Turning, on lathe with $80 \mathrm{HRC}$ hardness coated carbide insert on work material En9, 220 BHN of hardness during experimentation with parameters as time, tool acceleration and flank wear being measured at the end of each cut. The data is shown in table 1 .

The graphs of tool acceleration v/s tool wear are shown in fig 5 . The results of various combinations are plotted in graphs 1 to 8 , and from these it is seen that 2 peaks are obtained for each combination at different frequencies until maximum flank wear width of $0.6 \mathrm{~mm}$ is reached for coated carbide insert. This can be a base of establishing the relationship between vibration, acceleration amplitude and flanks wear. When anew, due to point contact of the cutting tool with the work piece there will be less friction between the tool and work piece, due to which the amplitude of vibration will be less while due to heaviness of work piece during early cutting stage, there will be an increase in vibration acceleration amplitude. The system characteristics are represented by this initial increase in the vibration acceleration amplitude. As the diameter and hence the mass of the work piece decreases, a corresponding decrease in vibration amplitude is observed. further increase in the tool wear brings a bit more surface contact work piece with tool due to which friction increases and therein the vibration acceleration amplitude as well, then the second peak appears. As the tool starts reaching its wear limit that is indicative of tool failure, the vibration acceleration amplitude drastically reduces. When compared with all the combinations of various operating conditions used for coated carbide inserts turning the tool steel En9 work material, the better tool life is attained with TMS1F1D1 that accounts to about 258 min of service.

Table 1: Data collected during experimentation during turning of combination TMS1F1D1

\begin{tabular}{|l|l|l|l|l|l|}
\hline SL. No. & $\begin{array}{l}\text { Cumulative } \\
\text { No of cuts }\end{array}$ & $\begin{array}{l}\text { Time for } \\
\text { one cut } \\
(\mathrm{min})\end{array}$ & $\begin{array}{l}\text { Cumulative } \\
\text { time (min) }\end{array}$ & $\begin{array}{l}\text { Tool } \\
\text { acceleration in } \\
\text { g's }\end{array}$ & $\begin{array}{l}\text { Progressive } \\
\text { flank wear } \\
(\mathrm{mm})\end{array}$ \\
\hline 1 & 2 & 6 & 12 & 0.3 & 0.03 \\
\hline 2 & 4 & 6 & 24 & 0.12 & 0.05 \\
\hline
\end{tabular}




\begin{tabular}{|l|l|l|l|l|l|}
\hline 3 & 8 & 6 & 48 & 0.12 & 0.07 \\
\hline 4 & 14 & 6 & 84 & 0.13 & 0.08 \\
\hline 5 & 16 & 6 & 96 & 0.18 & 0.11 \\
\hline 6 & 18 & 6 & 108 & 0.28 & 0.13 \\
\hline 7 & 21 & 6 & 126 & 0.18 & 0.16 \\
\hline 8 & 24 & 6 & 144 & 0.37 & 0.20 \\
\hline 9 & 26 & 6 & 156 & 1.0 & 0.26 \\
\hline 10 & 28 & 6 & 168 & 0.50 & 0.30 \\
\hline 11 & 30 & 6 & 180 & 0.43 & 0.33 \\
\hline 12 & 32 & 6 & 192 & 0.62 & 0.37 \\
\hline 13 & 34 & 6 & 204 & 1.0 & 0.48 \\
\hline 14 & 36 & 6 & 216 & 0.5 & 0.54 \\
\hline 15 & 38 & 6 & 228 & 0.43 & 0.56 \\
\hline 16 & 39 & 6 & 234 & 0.37 & 0.58 \\
\hline 17 & 43 & 6 & 258 & 0.37 & 0.60 \\
\hline
\end{tabular}

Table 2: Results of Turning with Various Combinations

\begin{tabular}{|l|l|l|l|l|l|l|l|}
\hline & 1st Peak & \multicolumn{2}{l|}{ 2nd Peak } & \\
\hline Combination & $\begin{array}{l}\text { Tool Acceleration in } \\
\text { g's }\end{array}$ & $\begin{array}{l}\text { Tool Wear in } \\
\mathrm{mm}\end{array}$ & $\begin{array}{l}\text { Tool Acceleration in } \\
\text { g's }\end{array}$ & $\begin{array}{l}\text { Tool Wear in } \\
\mathrm{mm}\end{array}$ & $\begin{array}{l}\text { Time } \\
\text { min }\end{array}$ & $\begin{array}{l}\text { No. } \\
\text { Cuts }\end{array}$ \\
\hline Coated Carbide Insert- En9 Tool Steel \\
\hline TMS1F1D1 & 1.0 & 0.26 & 1.0 & 0.48 & 258 & 43 \\
\hline TMS1F2D1 & 0.88 & 0.2 & 1.05 & 0.44 & 204 & 34 \\
\hline TMS2F1D1 & 1.0 & 0.23 & 1.09 & 0.5 & 190 & 38 \\
\hline TMS2F2D1 & 0.7 & 0.22 & 0.8 & 0.46 & 160 & 40 \\
\hline TMS1F1D2 & 1.0 & 0.3 & 0.95 & 0.54 & 144 & 36 \\
\hline TMS1F2D2 & 0.8 & 0.26 & 0.9 & 0.42 & 136 & 34 \\
\hline TMS2F1D2 & 1.5 & 2.1 & 0.47 & 108 & 36 \\
\hline TMS2F2D2 & 0.62 & 0.22 & 0.62 & 0.54 & 66 & 22 \\
\hline
\end{tabular}
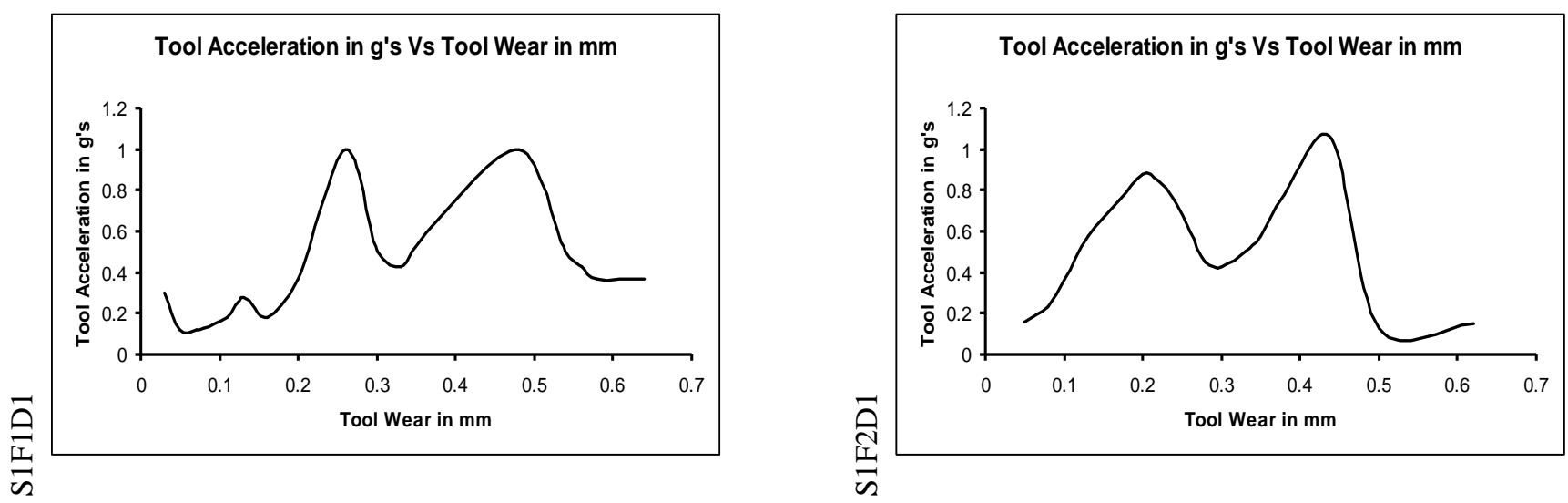

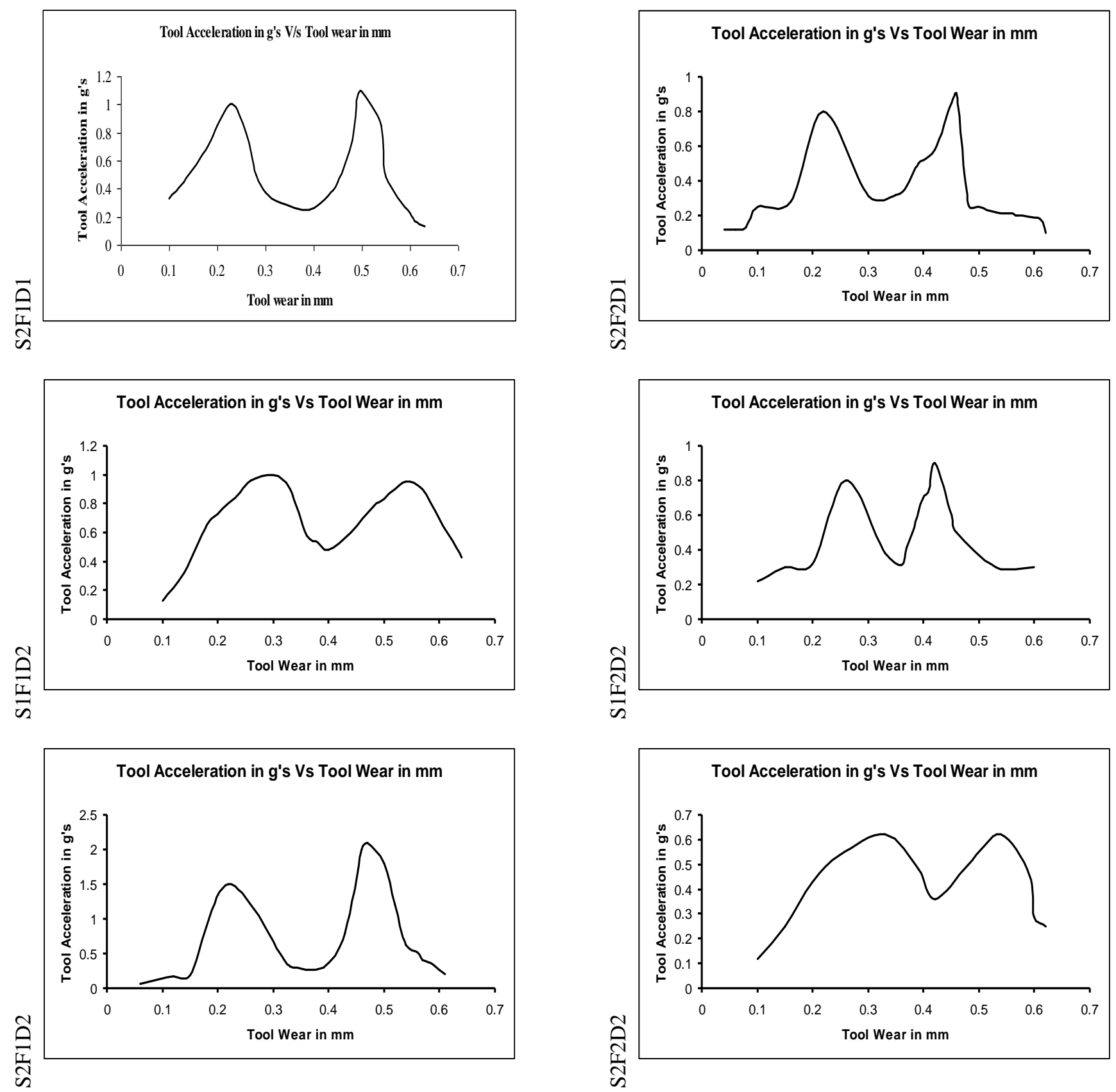

Fig 5: Graphs of tool acceleration v/s tool wear for coated carbide insert on En9

\section{REGRESSION ANALYSIS}

Regression analysis was carried out for experimental results of tool wear $\mathrm{v} / \mathrm{s}$ tool acceleration and regression trend was obtained for all combinations. The mapping of experimental and regression trends are shown in figure 6 . The regression equation that defines that trend was found to be a polynomial of 8th order. The regression values were obtained for all the input values of tool wear. Using the experimental and regression data the coefficient of determination R2 was calculated. These values were found to be more than 0.9 for almost all combinations, which are depicted in table 3. (11) 

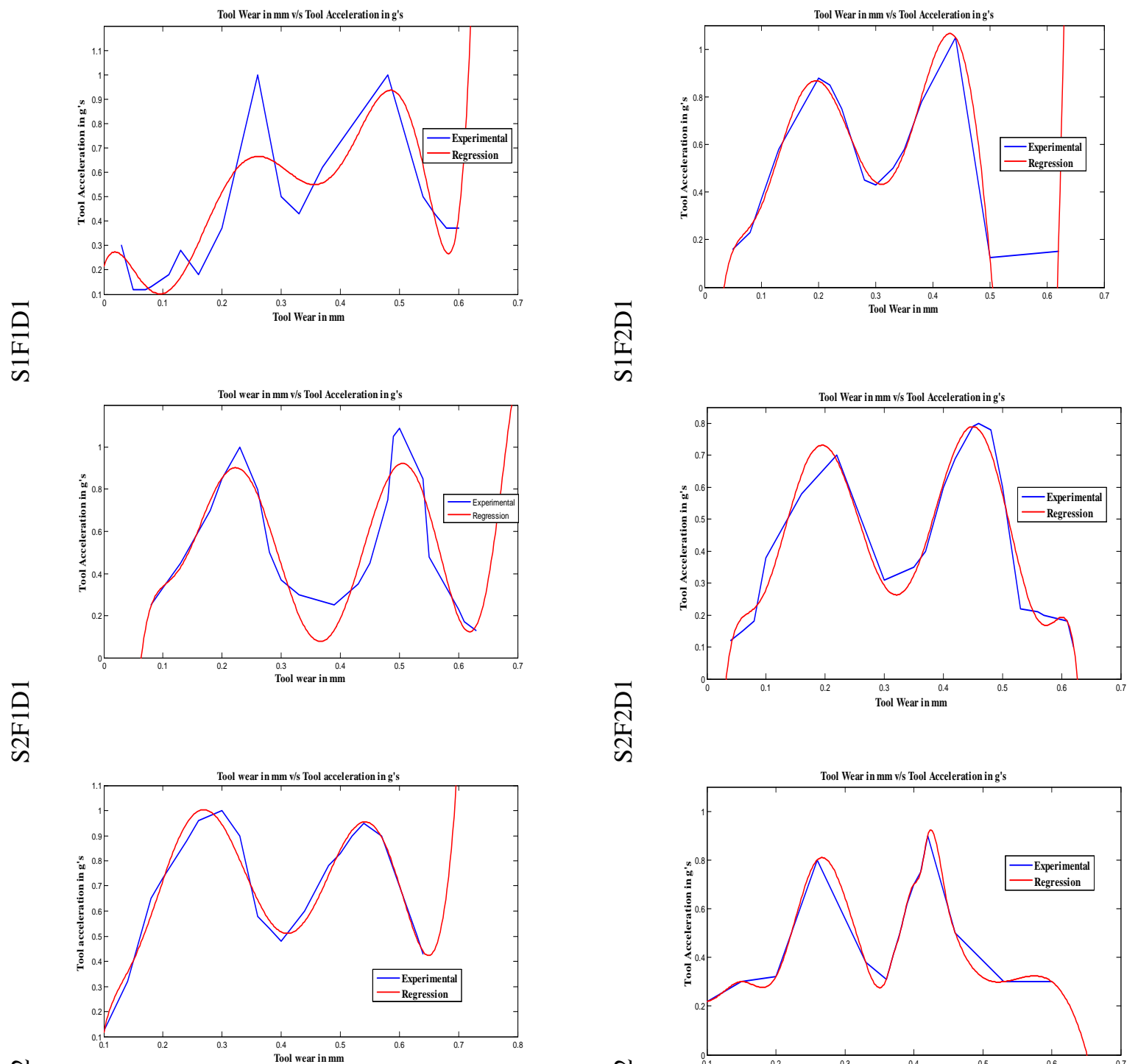

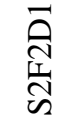
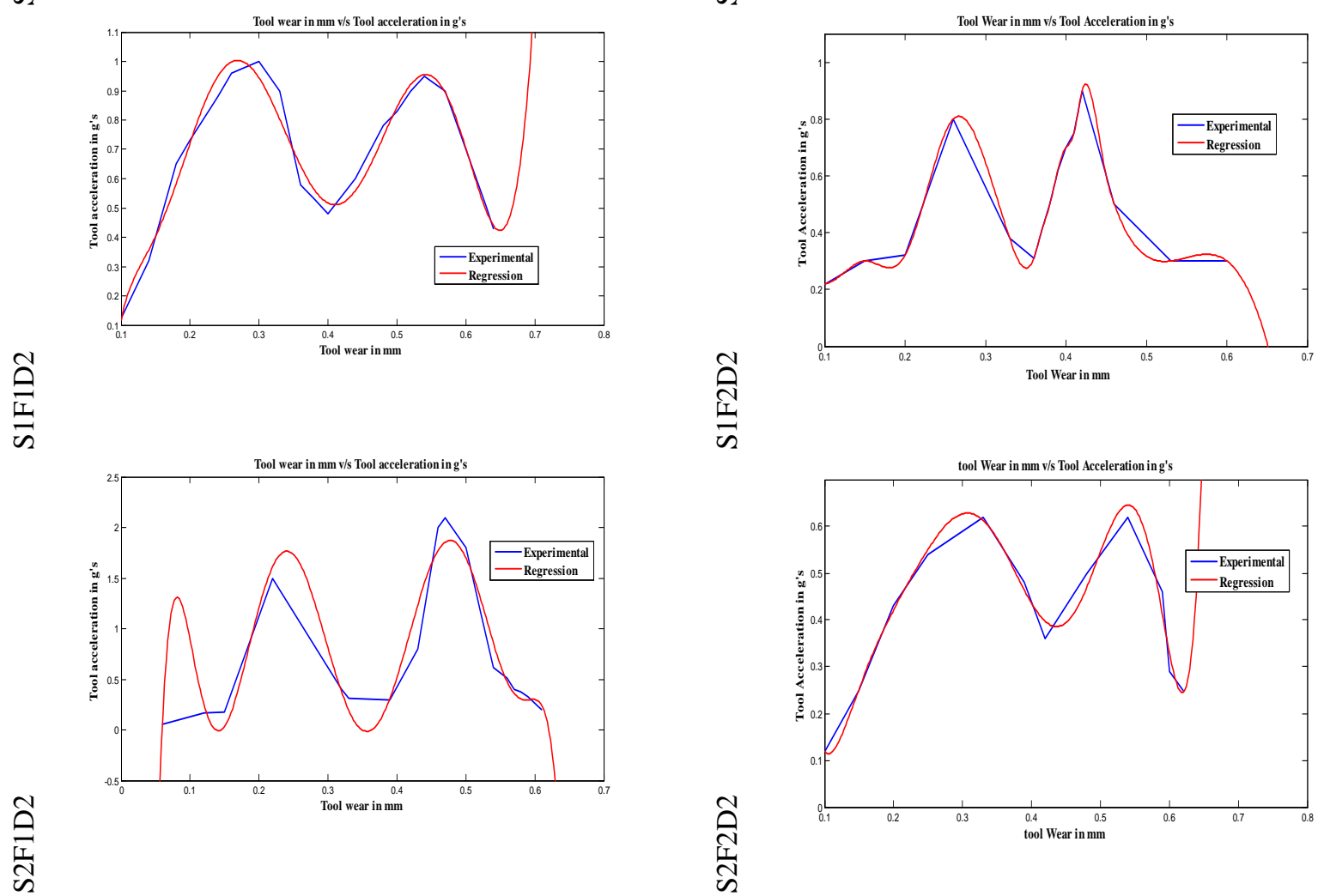

Fig 6: Regression graphs of tool acceleration v/s tool wear for coated carbide insert on En9 
Table 3: R Squared values for various combination

\begin{tabular}{|l|l|}
\hline Constants / Combinations & $\begin{array}{l}\text { Regression } \\
\text { Co-efficient of Determination R2 }\end{array}$ \\
\hline TMS1F1D1 & 0.78288 \\
\hline TMS1F2D1 & 0.9898 \\
\hline TMS2F1D1 & 0.8888 \\
\hline TMS2F2D1 & 0.9640 \\
\hline TMS1F1D2 & 0.9673 \\
\hline TMS1F2D2 & 0.8531 \\
\hline TMS2F1D2 & 0.9425 \\
\hline TMS2F2D2 & 0.9722 \\
\hline
\end{tabular}

\section{CONCLUSIONS}

The results of the research conducted with En9 work material machined against coated carbide inserts yields very positive results of using vibration monitoring technique to be used an on-line tool condition monitoring technique.

The graphs plotted from the results of experimental work carried out provide us the trends in which it is possible to know how tool flank wear progresses towards failure. This is possible to conclude even without disturbing the machining process with the use of trend developed which is the correlation of vibration amplitude of the tool during machining and the tool wear.

It is observed from all the graphs of tool acceleration in g's Vs tool wear in mm during the turning of tool steel En9 using coated carbide insert for various operating conditions used in the present research work that there are two peaks emerging at different frequencies before the carbide insert reaches the maximum flank wear of $0.6 \mathrm{~mm}$ in reference with ISO 3685 . The second peak can be considered as the warning peak as it occurs before the maximum tool wear is reached.

The regression analysis has shown that the co-efficient of determination and co-efficient of correlation were as high as 90\% and above. This implies how closely the regression values lye along with experimental values.

The trend helps us in timely replacement of the cutting tool so that the quality of the work under machining is no deteriorated. This attribute becomes very important during precision manufacturing and when there is risk of losing a fairly costly material for not reaching the specified quality standards.

This conclusion is possible because the resulting trend was obtained after conducting the experiments and also after conducting several repetitive trials for conformity of the results.

\section{REFERENCES}

[1] D. E. Dimla, Snr, "A Correlation of Vibration Signature Features to Cutting Tool Wear in Metal Turning Operation", the International Journal of Manufacturing Technology, Vol. 19, Number 10, Pages. $705-713,2002$

[2] G.H. Lim, "Tool Wear Monitoring in Machine Turning", Elsvier Journal of Material Processing Technology, 51(1995), Pages $25-36$

[3] Dragos .A. Axinte, Nabil Gindi, Kate Fox, Iker Unanue, "Process Monitoring to Assist the Work Piece Surface Quality in Machining", International Journal of Machine Tools \& Manufacture, Vol 44, Issue 10, August 2004, Pages $1091-1108$

[4] H. V. Ravindra, Y. G. Srinivasa and R Krishnamurthy, "Tool wear monitoring in turning using a pattern recognition technique", Journal of Materials processing technology, 37 (1993) 731-740

[5] N. Constantanides and S. Bennet,"An investigation of methods for the on-line estimation of tool wear", International journal of machine tools manufacture, volume 27, No. 2, pages 225-237, 1987

[6] T. N. Moore and Z. F. Reif, "The Determination of Cutting Tool Condition Using Vibration Signals", Proceedings of COMADEM 90, Brunel University, 16 -18 July 1990

[7] ISO 3685: 1993(E), International Standard, Second Edition, 1993-11-15

[8] Valery Marinov, "Manufacturing processes", Kandhall Publishers, 2006

[9] Vishal S. Sharma, S. K. Sharma and Ajay K. Sharma, "Cutting tool wear estimation for turning", Journal of Intelligent Manufacturing, Volume 19, Number 1, 99108, DOI: $10.1007 / \mathrm{s} 10845-007-0048-2$

[10] Hari Singh, "Optimizing tool life of carbide inserts for turned parts using Taguchi's design of experiments approach", Proceedings of the international multiconference of Engineers and computer scientists, 2008, 
Volume II, IMECS 2008, 19-21 March, 2008, Hong Kong

[11] D. E. Dimla, Snr, "A Correlation of Vibration Signature Features to Cutting Tool Wear in Metal Turning Operation", the International Journal of Manufacturing Technology, Vol. 19, Number 10, Pages. $705-713,2002$

[12] Mohamed Khaisar, K.V. Sreenivasa Prasad, "Wear Monitoring of Coated Carbide Inserts using Vibration Signal Processing during Turning of En9", International Journal of Advanced Manufacturing Systems, Vol. 3, Number 1, 2012, Pages 45-56 